\title{
EFFECTIVENESS OF A \\ COMMUNITY BASED PROGRAMME OF PHYSIOTHERAPY ON STABILITY, BALANCE AND FUNCTION OF STROKE PATIENTS
}

\begin{abstract}
This study assessed the effectiveness of a community based programme of physiotherapy on stability, balance and function in stroke patients. This observational cohort study enlisted twenty five patients with a first stroke receiving a programme of physiotherapy at a community based therapy center and monitored them over a seven month period. The Postural Assessment Scale for Stroke patients (PASS), Berg Balance Scale (BBS) and Barthel Index (BI) allowed assessment of stability, balance and function. The normalized data (PASS, BBS, BI) were subjected to Mann Whitney U tests $(p<0$. 05). Analysis of Variance was used to compare pre-test with post-test performance.

Pearson's correlation coefficients were computed for the relationship between PASS, BBS and BI scores pre and post-test. For the 12 PASS items, for 25 participants, a total of 50 improvements were noted. For the 14 items of the BBS, for 25 patients, a total of 51 improvements were noted.Normalized mean increases from pre to post-test were insignificant $(p<0.05)$ in all items. Overall PASS scores correlated with BBS scores $(r=0.84, p=0.000)$ and BI scores $(0.74, p=0.000)$. This outpatient based rehabilitation programme did not alter the functionality of patients over the study period and needs review.
\end{abstract}

\section{KEY WORDS: REHABILITATION, STROKE, COMMUNITY}

\section{INTRODUCTION}

In 2006, stroke was the leading cause of death and disability in South Africa with the potential to increase further due to increased exposure to risk factors (Bryer 2006). Although a proportion of these patients, $13 \%$ and $18 \%$ of males and females respectively over the age of 65 die from stroke (Bradshaw et al 2006), surviving stroke patients experience varying degrees of loss of function (Wasserman et al 2009).

Several studies have focussed on improving the quality of life of stroke survivors

\section{Corresponding Author:}

T. Puckree

Faculty of Health Sciences, Durban University of Technology,

Ritson Campus,

Durban, 4001

e-mail: puckreet@dut.ac.za through a variety of rehabilitation and other strategies including stroke units, improving instruments to measure quality of life, interventional studies (Yavuzer et al 2006) both hospital and community based (Wasserman et al 2009, Rhoda et al 2009). The movement towards randomized clinical trials support the determination of a treatment effect under controlled conditions. The clinical presentation by stroke survivors is very individualized and requires an individualized approach to achieve the best functional outcomes and hence clinical guidelines have been proposed (Duncan et al 2005). The actual rehabilitation programmes that patients receive in communities have not been evaluated despite the fact that these programmes could make a difference in the life of a stroke survivor.

In its efforts to provide health care to all, the South African Department of Health through its provincial departments has operated services in clinics attached to district based hospitals located in communities. The dire shortage of rehabilitation personnel like physiotherapists means that patients may only receive rehabilitation fortnightly at a community based therapy center from a physiotherapist or a physiotherapy assistant. This service has not been compared to guidelines proposed by the South African Stroke Society (Bryer et al 2010) or evaluated especially in view of the fact that all stroke related research aims at improving outcomes after stroke.

Postural control reflected in stability and balance is important to improve independence, social participation (Geurts et al 2005) and quality of life. The purpose of this study was to quantify the effect of a traditional programme of physiotherapy on stability, balance and function in a cohort of stroke survivors in a poorly resourced community setting. Qualitative information in the form of actual feelings and opinions about barriers to functionality was also explored. 


\section{METHODS}

The aims of this study were achieved using a quantitative survey supported by a qualitative component which allowed feedback from the participants about various items that affected their independence. All patients who suffered a first stroke and were aphasic but appeared cognitively functional who reported for therapy at a community based Assessment and Therapy Centre over a period of seven months were invited to participate in the study after fully informed consent. These patients were diagnosed by general practitioners in private practices and doctors at public clinics or hospitals. Patients were excluded if they had any previous lower limb fractures or were unable to participate in low intensity exercise programmes due to severe complications from co-morbidities, or were positive for Human Immunodeficiency Virus. Ethical clearance from the Institutional Research Ethics Committee, and other necessary approvals to conduct the study were obtained prior to data collection.

The physiotherapy programme for patients with strokes is an individualized one hour fortnightly session comprising of individual therapy by therapists or standardised group therapy administered by therapists or assistants. Patients who are mobile independently, either with or without an assistive device and require minimal individual attention are treated in the stroke group. Twenty five patients were identified for participation. The regular physiotherapy exercise programme included the exercises in Table 1.

The dependent variables of stability, balance and function were monitored using the Postural Assessment Scale for Stroke Patients (PASS) the Berg Balance Scale (BBS) and the Barthel Index (BI) respectively, pre-test and post-test. The PASS and BBS have been widely used, validated and tested for reliability (Mao et al 2003) on several patient populations. Participant personal details and feelings about the programme of exercises were captured on a questionnaire. On the first visit, the demographic questionnaire, PASS, BBS and BI were administered. Physiotherapy was continued for 12 sessions, fortnightly, for six months. The post-test scores and verbalizations were recorded after the last therapy sessions

The raw data was normalized by calculating percentage changes for each item for each participant. Data was nor-

\begin{tabular}{|l|l|}
\hline No & Exercise \\
\hline 1 & $\begin{array}{l}\text { Auto-assisted upper limb exercise for shoulder flexion and extension and } \\
\text { abduction and adduction }\end{array}$ \\
\hline 2 & Using momentum to roll to affected and unaffected sides \\
\hline 3 & Bridging with both lower limbs and bridging with affected lower limb \\
\hline 4 & Trunk rotations to affected and unaffected sides \\
\hline 5 & Joint approximation exercises in sitting \\
\hline 6 & Joint approximation exercises in standing \\
\hline 7 & Ball therapy for scapular movements using a medium sized ball \\
\hline 8 & Ball therapy for trunk dissociation using a big ball \\
\hline 9 & Hand activities \\
\hline 10 & Gait re-education in parallel bars or with an aid \\
\hline
\end{tabular}

Table 1: Exercise Program

malized to eliminate variations between participants because it was not possible to obtain a baseline with minimal variation. Normalized values were subjected to Mann Whitney U tests and paired samples $t$ tests to assess the effect of the programme post- test. Pearson's correlations allowed the determination of correlations between PASS, BBS, and BI. A p value $\leq 0.05$ was considered as statistically significant. All qualitative data was thematically arranged and the grounded theory was used to give meaning to the findings. This allowed one to compare quantitative data with the qualitative findings.

\section{RESULTS}

Twenty five participants completed the study protocol. Fourteen participants were affected on the right side, four hemiplegic and ten hemiparetic. Two patients were left hemiparetic and nine left hemiplegic. The ages of participants ranged from 35 to 76 years $($ Mean $=59$ years) with the majority between 50-74 years of age. Fifty six percent of the participants were female. Majority of participants were of Indian origin $(84 \%$; $\mathrm{p}<0.05)$ and the remainder were Black South Africans. Forty percent of the participants suffered the stroke six to 12 months ago compared to $48 \%$ reporting a stroke of less than six months. The remaining participants had the stroke for longer than one year.

Participants sought medical attention from private or public sector local clinics and medical practitioners at the time of their attacks. Of the eight participants who had not attended a hospital following their attacks, three reported 'having no finances' whilst five complained about the 'long queues at the hospitals.'
Participants indicated that they were not aware of the cerebrovascular incident (ischemic or hemorrhagic) which resulted in their stroke. Hypertension was reported as a significant cause of the attack (44\%). Other co-morbidities like Diabetes Mellitus, Hyperlipidemia and blood clots were also mentioned but accounted for less than 20\%. About four percent of participants reported having no known cause to their attacks.

All participants were functional using an assistive device. The most commonly used walking device was either a quadripod $(40 \%)$ or an elbow crutch $(36 \%)$. The remaining patients used either a walking stick or a wheel chair in equal proportions.

\section{ASSESSMENT OF STABILITY}

Table 2 shows the numbers and percentages of optimal scores on pre-test and post-test, improved scores and normalized mean percentage increase per PASS item.

Thirty three percent of all scores on pretest were optimal compared to $44 \%$ posttest indicating a ten percent increase in optimal scores. As seen in Table 2 for Item 1 , the majority of participants scored optimal scores on pre-test. Table 2 also shows means of normalized percentage changes in score by item for the comparisons between the pre-test and post-test. The mean increase was almost five percent.

\section{ASSESSMENT OF BALANCE}

Table 3 shows the numbers and percentages of participants who had optimal scores or had improved scores from the pre-test to post-test on individual items of the BBS.

Only six percent of optimal scores were noted on pre-test and eight per- 
cent on post-test with only $14.6 \%$ of improved scores. The majority of optimal scores on pre-test were noted for item 1, but a few were noted on post-test. No optimal scores were observed on pretest for the remaining items. As seen in Table 3, normalized mean increases in scores improved by just three percent.

\section{ASSESSMENT OF FUNCTION}

As shown in Table 4 more optimal scores on pre-test were observed for self-care items (BI Items: 2, 3, 4, and 7) of the BI, compared to mobility and stability (BI Items: 8, 9, and 10) items. Only four percent more optimal scores were observed on post-test compared to pre-test. Overall a mean of five percent improved scores were noted. Normalized mean improvement was just one percent with the greatest increase in stair climbing.

\section{RELATIONSHIP BETWEEN PASS, BBS AND BI SCORES}

As shown in Table 5, a moderate to strong correlation existed between PASS and $\mathrm{BBS}, \mathrm{PASS}$ and $\mathrm{BI}$ and $\mathrm{BBS}$ and $\mathrm{BI}$ scores.

\section{VERBAL INPUT}

All participants stated that they could sit without support, however, if the height of the seat from the floor varied, $12 \%$ reported they would have difficulty getting into and out of the chair.

Twelve percent needed assistance with their 'food being cut up' when eating. None of the participants had problems with chewing or swallowing food. Forty four percent of the participants reported degrees of difficulty with dressing. Some needed total assistance whilst others were unable to fasten 'buttons', 'zips' or 'tie shoe laces.' In the post-test interview, four percent verbalized that their dressing had become easier and more independent. Eighty eight percent stated that their standing and walking balance was poor. The stroke affected their confidence about their walking balance since they were unstable on their feet. In the post-test interview, 56\% reported a 'great improvement' in their standing balance. Participants reported 'stumbling' and 'forgetting about the stroke side' as their biggest hurdles when performing daily activities. Balancing during activities such as sitting down and standing up from a toilet and getting into and out of a bath or shower posed a problem with $76 \%$ of the participants in the pre-test interview. However after the physiotherapy programs, 20\% reported an overall improvement in their balance regarding daily activities.

\section{DISCUSSION}

All participants attended all sessions of the minimal standard of care physiotherapy programme. This programme was not benchmarked against the guidelines set down by the South African Stroke Association (Bryer et al 2010). The demographic profile of the participants is similar to that described in the literature (Bradshaw et al 2006, Yavuzer et al 2006, Maron et al 2002), namely a variety of presentations in keeping with the nature of the condition, similar age with the majority between 50 and 74 years of age. The participants' gender distribution did not deviate from that described in the literature (Bradshaw et al 2006, Maron et al 2002). Since the therapy center is located in a former designated area for South Africans of Indian descent and still largely populated by Indians, the majority of the participants were from this race group. The stage of the stroke ranged from sub acute to chronic and the majority of participants were mobile with an assistive device which is in line with the functional capability of stroke survivors.

The patients in our study sought medical care late or not at all for a variety of reasons. These reasons are different from the ones described by Yu et al (2002). The main reason for not seeking

\begin{tabular}{|l|l|l|l|l|l|}
\hline \multicolumn{2}{|l|}{ PASS Item } & $\begin{array}{l}\text { Optimal scores } \\
\text { on pre-test } \\
\text { Number (\%) }\end{array}$ & $\begin{array}{l}\text { Improved } \\
\text { Number (\%) }\end{array}$ & $\begin{array}{l}\text { Optimal scores } \\
\text { on post test } \\
\text { Number (\%) }\end{array}$ & $\begin{array}{l}\text { Mean } \\
\text { normalized \% } \\
\text { change }\end{array}$ \\
\hline 1 & Sit with support & $22(88)$ & 0 & $22(88)$ & 0 \\
\hline 2 & Stand without support & $14(56)$ & $3(12)$ & $17(68)$ & 3 \\
\hline 3 & Stand without support & $6(24)$ & $10(40)$ & $12(48)$ & 7 \\
\hline 4 & Stand on non paretic staff & $16(64)$ & $3(12)$ & $13(52)$ & 3 \\
\hline 5 & Stand on paretic leg & $4(16)$ & $6(24)$ & $8(32)$ & 6 \\
\hline 6 & Roll from supine to affected side & $10(40)$ & $3(12)$ & $12(48)$ & 3 \\
\hline 7 & Roll supine to unaffected side & $7(28)$ & $7(28)$ & $13(52)$ & 7 \\
\hline 8 & Supine to sitt on edge of bed & $7(28)$ & $3(12)$ & $9(36)$ & 3 \\
\hline 9 & Sit on edge of bed & $7(28)$ & $3(12)$ & $9(36)$ & 3 \\
\hline 10 & Sit to stand without support & $2(8)$ & $4(16)$ & $4(16)$ & 4 \\
\hline 11 & Stand to sit without support & $12(48)$ & $3(12)$ & $4(16)$ & 3 \\
\hline 12 & Stand and pick object from floor & $0(0)$ & $5(20)$ & $4(16)$ & 5 \\
\hline Total & & $100(33.3)$ & $50(16.7)$ & $133(44)$ & $4.89 *$ \\
\hline
\end{tabular}

Table 2. Numbers and percentages of participants with optimal scores on pre-test and post-test, and improved scores on individual items of the PASS and normalized mean percentage increase per PASS item. * $=$ mean normalized $\%$ change 


\begin{tabular}{|l|l|l|l|l|l|}
\hline \multicolumn{2}{|l|}{ BBS Item } & $\begin{array}{l}\text { Optimal score } \\
\text { on pre-test } \\
\text { Number (\%) }\end{array}$ & $\begin{array}{l}\text { Improved } \\
\text { Scores } \\
\text { Number (\%) }\end{array}$ & $\begin{array}{l}\text { Optimal score } \\
\text { on post- test } \\
\text { Number (\%) }\end{array}$ & $\begin{array}{l}\text { Mean } \\
\text { normalized \% } \\
\text { change }\end{array}$ \\
\hline 1 & Sitting unsupported & $22(88)$ & $0(0)$ & 22 & 0 \\
\hline 2 & Sitting to standing & $0(0)$ & $11(44)$ & 2 & 4 \\
\hline 3 & Standing to sitting & $0(0)$ & $10(40)$ & 2 & 8 \\
\hline 4 & Transfer from one chair to another & $0(0)$ & $1(4)$ & 0 & 0.8 \\
\hline 5 & Standing unsupported & $0(0)$ & $4(16)$ & 1 & 3.2 \\
\hline 6 & Standing with eyes closed & $0(0)$ & $3(12)$ & 0 & 2.4 \\
\hline 7 & Standing with feet together & $0(0)$ & $0(0)$ & 0 & 0 \\
\hline 8 & $\begin{array}{l}\text { Standing with 1 foot in front of the } \\
\text { other }\end{array}$ & $0(0)$ & $2(8)$ & 1 & 1.6 \\
\hline 9 & Standing on one leg & $0(0)$ & $6(24)$ & 0 & 4.8 \\
\hline 10 & Turning trunk with feet fixed & $0(0)$ & $4(16)$ & 0 & 3.2 \\
\hline 11 & Retrieving objects from floor & $0(0)$ & $2(8)$ & 0 & 1.6 \\
\hline 12 & Turn 360 degrees & $0(0)$ & $2(8)$ & 0 & 1.6 \\
\hline 13 & Stool stepping & $0(0)$ & $3(12)$ & 0 & 2.4 \\
\hline 14 & Reaching forward while standing & $0(0)$ & $4(16)$ & 0 & 2.4 \\
\hline Total & & $22(6)$ & $51(14.6)$ & $28(8)$ & $2.6 *$ \\
\hline
\end{tabular}

Table 3. Numbers and percentages of participants with optimal scores on pre-test and post-test, and improved scores on individual items of the BBS and normalized mean percentage increase per BBS item. * = mean normalized \% change

immediate medical care was an inability to recognize symptoms is different from that reported by participants in our study.

It is accepted that all patients require at least a minimal standard of care which should follow clinical practice guidelines (Duncan et al 2005). The rehabilitation of stroke patients in and out of rehabilitation facility settings has received extensive attention in the scientific literature (Duncan et al 2005, Rhoda et al 2009). The extent to which research findings have been translated into evidence based practice and the effectiveness of these applications in real settings has received some attention (Duncan et al 2005). The minimal standard of care physiotherapy programme offered to stroke survivors attending an outpatient community based therapy center over a period of six months showed no real change in functional outcomes in the cohort. The stroke survivors in our study had minimal or no inpatient care due to their social circumstances and the demand for health care services at public institutions. Indredavik et al (1991) found that acute care in a stroke unit improved quality of life at 5 years.

It is clear that a well organized multidis- ciplinary approach together with compliance to guidelines for stroke rehabilitation in post-acute stroke is necessary to ensure improved patient outcomes (Duncan et al 2005, Rhoda et al 2009). Compliance with guidelines is a quality of care indicator (Reker et al 2002). The programme of physiotherapy in our study clearly did not follow the guidelines for stroke care but incorporated the principles of neurodevelopmental theory (Duncan et al 2005). Rhoda et al (2009) reported a lack of occupational and speech therapy services at community based stroke rehabilitation centres included in their study. In addition it was found that where services were available, uptake was low and could be due to problems relating to access. The findings of our study cannot be compared to other similar studies since none exist. In 1999, Cifu and Stewart (1999) indicated that the available literature is insufficient to assess the relationship of specific types of non-inpatient rehabilitation services and functional outcomes. This situation has not changed.

The insignificant improvements in Barthel Index scores in this study follow the trend seen for the stability and balance scores. The fact that the rehabilitation following stroke is multifaceted and requires a flexible approach (Duncan et al (2005) is beyond the scope of practice of a physiotherapy assistant. These factors could have affected the outcomes and should be followed up. The minimal improvement in the number of optimal PASS scores post-test could be attributed to a variety of factors including the nature of the therapy. The physiological and functional stresses associated with participants attending the therapy center as well as the spontaneous recovery may be variable and difficult to assess. The fewer increases in optimal scores and lower mean increase in BBS scores may relate to the fact that stability is required for balance. The increases in PASS scores may not have translated into measurable balance increases in the time frame of the study. In addition the measurement instrument may not have been sensitive enough to detect small changes.

Daving (2013) noted that the control of measurement strategies is important in ensuring that assessments are reproducible and enable the best conclusions to be drawn. The PASS, BBS and BI have been tested, and used in several scientific investigations (Geurts et al 2005, Januario et al 2010).

Although the compliance of the partici- 
pants in following through with activities included in the physiotherapy programme was monitored through verbal feedback, neural plastic changes are contingent on practice and sustained practice and reflect in functional changes. The compliance of patients to the programme of therapy, in the interval between sessions should be monitored closely.

A very clear interdependence between stability, balance and function is noted as measured revealed by the correlational statistics. Michael et al (2005) following a study on ambulatory activity in community dwelling chronic stroke survivors concluded that mobility deficits especially in balance were associated with low ambulatory activity. They suggested further studies in which the effects of balance related activities should be investigated.

\section{CONCLUSION}

This study showed that the community based physiotherapy programme was not effective in improving stability, balance and function in the population under study. In addition a clear interdependence between stability, balance and functional scores suggests the need for a more focussed programme of outpatient therapy. This study is important in realizing the goals of all stroke research namely to ultimately improve the quality of life of stroke survivors through effective programmes of therapy.

\section{REFERENCES:}

Bradshaw D, Schneider M, Norman R, Bourne D. 2006 Mortality patterns of chronic diseases of lifestyle in South Africa. In: Steyn K, Fourie J, Temple N (eds) Chronic diseases of lifestyle in South Africa 1995 2005. Pp15, MRC, Tygerberg

Bryer CM 2006 Stroke in South Africa. In: Steyn K, Fourie J, Temple N (ed) Chronic diseases of lifestyle in South Africa 1995-2005, pp195-203. MRC, Tygerberg

Bryer A, Connor MD, Haug P, Cheyip B, Staub H, Tipping B, Duim WB, Pinkney-Atkinson V 2010 South African guidelines for the management of ischaemic stroke and transient ischaemic attach: 2010 A guideline from the South African Stroke Society (SASS) and the SASS writing committee. South African Medical Journal 100: 750-788

Cifu DX, Stewart DG 1999 Factors affecting functional outcome after stroke: a critical review of rehabilitation interventions. Archives of Physical Medicine and Rehabilitation 80: S35-S39

Daving Y 2009 ADL Assessment after stroke: aspects on reliability like stability between raters, instruments and modes of administration. Unpublished dissertation University of Gothenburg, Goteborg, Sweden.

\begin{tabular}{|l|l|l|l|l|l|}
\hline \multicolumn{2}{|l|}{ BI Items } & $\begin{array}{l}\text { Optimal } \\
\text { scores on } \\
\text { pre-test } \\
\text { Number (\%) }\end{array}$ & $\begin{array}{l}\text { Improved } \\
\text { scores } \\
\text { Number (\%) }\end{array}$ & $\begin{array}{l}\text { Optimal } \\
\text { scores on } \\
\text { post-test } \\
\text { Number (\%) }\end{array}$ & $\begin{array}{l}\text { Mean } \\
\text { normalized } \\
\text { change }\end{array}$ \\
\hline 2 & Bathing & $16(68)$ & $0(0)$ & $16(68)$ & 0 \\
\hline 3 & Grooming & $14(56)$ & $0(0)$ & $14(56)$ & 0 \\
\hline 4 & Dressing & $9(36)$ & $1(4)$ & $9(36)$ & 2 \\
\hline 7 & Toilet & $13(52)$ & $1(4)$ & $14(56)$ & 2 \\
\hline 8 & Transfers & $3(12)$ & $3(12)$ & $5(20)$ & 4 \\
\hline 9 & Mobility & $3(12)$ & $3(12)$ & $6(24)$ & 4 \\
\hline 10 & Stairs & $0(0)$ & $6(24)$ & $4(16)$ & 12 \\
\hline Total & $58(23)$ & $14(5)$ & $68(27)$ & 1 * \\
\hline
\end{tabular}

Table 4. Numbers and percentages of participants with optimal scores on pre-test and post-test, and improved scores on selected individual items of the $\mathrm{BI}$ and normalized mean percentage increase per $\mathrm{BI}$ item. * = mean normalized \% change

\begin{tabular}{|l|l|l|l|l|}
\hline & $\begin{array}{l}\text { BBS Pre-test } \\
\mathbf{r}(\mathbf{p})\end{array}$ & $\begin{array}{l}\text { BBS Post-test } \\
\mathbf{r}(\mathbf{p})\end{array}$ & $\begin{array}{l}\text { BI pre } \\
\mathbf{r}(\mathbf{p})\end{array}$ & $\begin{array}{l}\text { BI post } \\
\mathbf{r}(\mathbf{p})\end{array}$ \\
\hline $\begin{array}{l}\text { PASS } \\
\text { Pre-test }\end{array}$ & $0.846(0,000)$ & $0.847(0,000)$ & $0.734(0,000$ & $0.737(0.000)$ \\
\hline $\begin{array}{l}\text { PASS } \\
\text { Post-test }\end{array}$ & $0.993(0.000)$ & $0.846(0.000)$ & $0.733(0.000)$ & $0.741(0.000)$ \\
\hline $\begin{array}{l}\text { BBS } \\
\text { Pre-test }\end{array}$ & & $0.891(0.000)$ & $0.707(0.000)$ & $0.632(0.001)$ \\
\hline $\begin{array}{l}\text { BBS } \\
\text { Post-test }\end{array}$ & & & $0.649(0.000)$ & $0.690(0.000)$ \\
\hline $\begin{array}{l}\text { BI } \\
\text { Pre-test }\end{array}$ & & & & $0.795(0.000)$ \\
\hline
\end{tabular}

Table 5: Pearson's correlation coefficients and $p$ values of overall mean PASS and BBS scores for the pre-test and post-test for the group. ( $p$ values in parentheses)

http://gupea.ub.gu.se/bitstream/2077/19057/1/ gupea_2077_1. Accessed 24 January 2013

Duncan PW, Zorowitz R, Bates B, Choi JY, Glasberg JJ, Graham GD, Katz RC, Lamberty K, Reker D 2005 Management of Adult Stroke Rehabilitation Care A Clinical Practice Guideline. Stroke 36: e100-e143

Geurts AC, de Haart M, van Nes IJ, Duysens J 2005 A review of standing balance recovery from stroke. Gait Posture 22: 267-81

Indredavik B, Bakke F, Solberg R, Rokseth $\mathrm{R}$, Haaheim LL, Holme I 1991 Benefit of a stroke unit: a randomized controlled trial. Stroke 22: 1026-1031

Januario F, Campos I, Amaral C 2010 Rehabilitation of postural stability in ataxic/hemiplegic patients after stroke. Disability and Rehabilitation 32:1775 - 1779

Mao H, Hsueh I, Tang P, Sheu C, Hsieh C 2003 Analysis and Comparison of the Psychometric Properties of three Balance Measures for Stroke patients. Stroke 34:1741-1745

Maron BJ, Olivotto I, Bellone P, Conte MR, Cecchi F, Flygenring BP, Casey SA, Gohman TE, Bongioanni S. Spirito P 2002 Clinical profile of stroke in 900 patients with hypertrophic cardiomyopathy. Journal of the American College of Cardiology 39:301-7
Michael KM, Allen JK, Macko RF 2005 Reduced ambulatory activity after stroke: the role of balance, gait, and cardiovascular fitness. Archives of Physical Medicine and Rehabilitation 86:1552-1556

Reker DM, Duncan PW, Horner RD, Hoenig H, Samsa GP, Hamilton BB, Dudley TK 2002 Postacute stroke guideline compliance is associated with greater patient satisfaction. Archives of Physical Medicine and Rehabilitation 83: 750-756

Rhoda A, Mpofu R, DeWeerdt W 2009 The rehabilitation of stroke patients at community health centres in the Western Cape South African Journal of Physiotherapy 65(3): 1-6

Yavuzer G, Eser F, Karakus D, Karaoglan B Stam IJ 2006 The effects of balance training on gait late after stroke: a randomized clinical trial. Clinical Rehabilitation 20:960-9

Yu RF, Cristina M, San Jose Z, Manzanilla BM, Oris MY, Gan R 2002 Sources and reasons for delays in the care of acute stroke patients Journal of Neurological Sciences 199: 49-52

Wasserman S, de Villiers L, Bryer A 2009 Community -based care of stroke patients in a rural African setting. South African Medical Journal 99: 579-583 